\title{
Evaluation of Antimicrobial Efficacy of Lyophilized Platelet Lysate against Organisms Isolated from Infected Root Canals: An in vitro Study
}

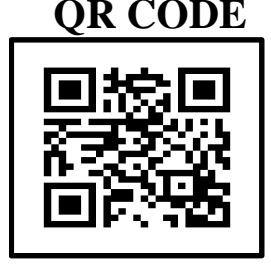

ARVIND KUMAR', TL SUGANYA²

INTRODUCTION: The technically demanding endodontic treatment sometimes faces failures because of various polymicrobial infections. Common organisms isolated from such infections are Enterococcus faecalis and Candida albicans. Several researches were made with various materials to eradicate such organisms. The study material used here is Lyophilized platelet rich plasma (L-PRP), which has been recently used in dentistry and other medical fields to promote hard and soft tissue regeneration.

AIM: The aim of this in vitro study was to evaluate the antimicrobial efficacy of lyophilized platelet lysate (LPL) against microorganisms like Enterococcus Faecalis, Bacillus Subtilis and Candida Albicans.

MATERIALS AND METHOD: Discarded blood samples were obtained from blood banks after centrifugation, sterility check and activation. After this, lyophilization of the platelets was carried out. The antimicrobial activity of this freeze dried powder was evaluated by the minimum inhibitory concentration method and then by the Agar disk diffusion method.

RESULTS: Lyophilized platelet lysate (LPL) inhibited the growth of Enterococcus faecalis, Bacillus subtilis and Candida albicans which is commonly associated with failed root canal treatment.

CONCLUSION: LPL has the potential to be effective against the organisms which causes failure of root canal treatment. This can be of a valuable property in tissue engineering.

KEYWORDS: Lyophilized Platelet Lysate (LPL), Antimicrobial Activity, Minimum Inhibitory Concentration, Post Endodontic Infections, Agar Disc Diffusion

\section{INTRODUCTION}

The greatest challenge associated with failed root canals in clinical research is the development of surgical additives like the fibrin glue that reduces inflammation and enhance the healing process. ${ }^{1}$ For the past two decades many bioactive materials have been introduced in dentistry which are effective in their own way. Similarly it is of significance to know about the material which seeks major attention currently which is the autologous platelet concentrates (PCs). These platelet preparations excel both in the medical and dental field due to their excellent hemostasis and also for their hard and soft tissue regeneration properties. This is due to the abundant proteins and growth factors which are present in them. In spite of their superior properties these PCs are not commonly used in clinical practice because of the long working time, the availability of equipment and also due to the short storage time. To overcome these disadvantages the platelet concentrates are now available in the freeze dried form commonly known as lyophilized platelet lysate (LPL).

Lyophilized platelet lysate (LPL) is a granular powder derived from the human blood which contains proteins and growth factors. These are lyophilized for long term storage and also for stability. Many researches have described the healing potential and also the hemostasis of platelet preparations, but only recently its antimicrobial property is gaining recognition. This is the first study to evaluate the antimicrobial property of the freezed platelet concentrates ( LPL). ${ }^{2}$

E. feacalis is a gram positive cocci and a facultative anaerobe that occurs singly in pairs or in short chains. Its cell wall contains large amount of peptidoglycan and teichoic acid. It has the ability to survive in the root canal as a single organism without other bacterial support. Upon contamination of the root canal with this bacterium, it colonizes the dentinal walls under stressful conditions like endodontic medicaments and nutrient deficiency. The most common challenge in current endodontic practice is the eradication of $\mathrm{E}$. feacalis from root canals especially in failed cases. This is due to its peculiar ability to survive even in high alkaline environment and it is also seen to be the most commonly associated microorganism with persistent periapical lesions after completion of endodontic treatment. ${ }^{3}$

Candida albicans is a diploid fungus which is a part of the normal microflora but has also occasionally been reported in failed root canals. The pathogenicity of this organism is dependent upon local and systemic factors affecting the host. ${ }^{4}$

Bacillus subtillis, a rod shaped gram positive and catalyst positive bacteria. It produces various array of structurally unrelated antimicrobial proteins like lipopeptides and 
bacteriocin like inhibitory substances which modify their outer structure which helps in regrouping the organisms for proliferation and spreading. The spores of these strains can be present in unsterilized gutta-percha cones when these are used as the root canal filling material. This can cause bacterial contamination when it comes in contact with the peri-radicular tissues. ${ }^{5}$

\section{MATERIALS AND METHODS}

The study material used here is the Lyophilized platelet lysate obtained from Mother Cell Regenerative Centre, Trichy.

\section{Preparation of lyophilized platelet lysate}

Fresh Platelet rich plasma units are obtained from buffy coats and are immediately used for the preparation of LPL, as the old platelet concentrates have in them a reduced number of growth factors which is due to the storage and degradation process.

Sterility check: Discarded platelet concentrates (after 5 days of preparation) which are prepared by apherisis method and stored in plastic bags are obtained from the blood bank (Doctors Diagnostic Center, Trichy). Each bag contains $45-50 \mathrm{ml}$ of leucoreduced buffy coat. Sterility check is carried out before pooling the samples.

Pooling of buffy coats: Two buffy coat units were pooled and $2 \mathrm{ml}$ of the sample was removed to enable for the platelet count. The content of the platelet concentrates are transferred as a $30 \mathrm{ml}$ in a sterile $50 \mathrm{ml}$ centrifuge tube (Tarson New Delhi).

Platelet counting: The number of platelets were counted by photometric method ${ }^{6}$ before the freeze thaw cycle. A platelet reagent (Lyse-S III lytic reagent) was added as per the manual provided by Biolab Diagnostics, India. Approximately $18.5 \pm 2.3 \times 109$ Cells / ml was used for this study.

Removal of WBC \& RBC Residues: The pooled buffy coats were centrifuged at $250 \mathrm{~g}$ for $10 \mathrm{mins}$ at $4^{\circ} \mathrm{C}$ in order to remove traces of leucocytes. After centrifugation the plasma was then transferred to another sterile tube without disturbing the pellet. This platelet contains traces of RBC and WBCs.

Platelet Fragmentation (Activation): The platelets were then activated by means of repeated freeze thawing cycle by placing it first at $-40^{\circ} \mathrm{C}$ for $25 \mathrm{~min}$ and then immediately it was transferred to a $37^{\circ} \mathrm{C}$ water bath for 10 min. This cycles was then repeated three times in order to release the growth factors by breaking the platelet membrane.

Removal of platelet fragments: The platelet membranes were then removed by passing the content through a series of cell strainers measuring $100 \mu \mathrm{m}, 70$ $\mu \mathrm{m}, 40 \mu \mathrm{m}$, (TCP 181-3; HiMedia, Mumbai, India) respectively and finally placing it in a centrifuge at 4000 $\mathrm{g}$ for 15 minutes.

Lyophilisation of Platelet Lysate: The activated platelet sample was frozen at $-40^{\circ} \mathrm{C}$ and then was taken for freeze-drying in a laboratory-scale freeze-drier (EBT121, India). The freeze-drier cabinet was precooled to $-40^{\circ} \mathrm{C}$ and the frozen activated platelet was then placed on the shelf of the cabinet. During the drying process, the vacuum chamber pressure was kept at about $5 \mathrm{~Pa}$. Depending upon the volume of the samples placed the drying time lasted for between 48 to 70 hrs. After freezedrying, the samples were removed aseptically, EO Sterilized and then stored at room temperature. Lyoprotectants like trehalose and bovine serum albumin were not used as the aim was to lyophilize the growth factors.

Bacterial strains: Organisms such as E.feacalis (MTCC), Candida albicans and Bacillus subtillis are obtained from the Indian institute of microbial technology, Chandigarh, India and stored in cryoprotectant medium (brain-heart infusion broth) at $-80^{\circ} \mathrm{C}$ to suspend metabolism. Before use, the microbial cultures were recovered by thawing and seeding on the appropriate solid medium. E. faecalis and B.subtilis were seeded on trypticase soy agar and incubated for 24 hours at $37^{\circ} \mathrm{C}$. C. albicans was seeded on to Sabouraud dextrose Agar.

Determination of the Antimicrobial property: To determine the antimicrobial property, first the minimum inhibition concentration of the drug was determined and then the inhibitory zone was measured by using the disc diffusion method.

Disc diffusion method: This was performed by determining the Zone of Inhibition, which is a rapid and inexpensive way to determine the susceptibility of a particular antigen to the bactericidal agent applied. This was executed by measuring the diameter $(\mathrm{mm})$ of the area that stays clear of microbial growth by using a vernier caliper for this method and standard antibiotic disks were purchased (HIMEDIA Laboratories, India). Each disk had a diameter of $6 \mathrm{~mm}$ and was loaded with 10 to $60 \mathrm{mg}$ of the sample and then it was air dried. 
Bacterial cultures of about $106 \mathrm{CFU} / \mathrm{mL}$ was plated on to the LB agar plate onto which the loaded disks were placed and incubated at $37^{\circ} \mathrm{C}$ for $18 \mathrm{hrs}$. The diameters of the zone of inhibition were measured and the assays were then performed in triplicate (Table 1).

\section{Statistical analysis}

The collected data were expressed in the mean \pm standard deviation mode. $P$ values were calculated using the Chi Square test by the SPSS 21.0 software.

\section{RESULTS}

The minimum inhibitory concentration of LPL is shown in Table 1. Antimicrobial Activity of Tested Sample of the three organisms is shown in Table 2. The minimum inhibition zone of the three organisms LPL showed greater inhibition Zone For E. feacalis followed by C. albicans and Bacillus Subtilis.

\section{DISCUSSION}

Bacterial infection is one of the most serious complications impairing wound healing and tissue regeneration. Even after applying strict disinfection, bacteria can infiltrate and colonize the underlying tissues. The combination of proteolytic enzymes, chronic inflammation, toxin-rich bacterial exudates can alter the growth factors and metalloproteinases, thereby affecting the cellular components needed for cell proliferation and wound healing. ${ }^{7}$

The main goal of endodontics is to restore the form of the tooth and peri-radicular tissues without any postoperative infections. But achieving this is always a great challenge. For the past two decades regeneration potential of platelet concentrates has the subject of interest among various researchers. But there are only few articles supporting its antimicrobial property.

As the platelet concentrates are a complex mixture of platelets ,WBC's and plasma the antibacterial property of platelets alone is poorly understood .Several results have shown that the antibacterial activity is due to the antimicrobial proteins and peptides of immune defense such as platelet factor-4, RANTES, ${ }^{8,9}$ Thymosin-4, Connective tissue activating peptide 3 , Fibrinopeptide ${ }^{10} \mathrm{~A}$ and B, Human beta defensin-3, Platelet Basic Protein, and the alpha granular Components Like Complement binding proteins. ${ }^{11,12}$

For antimicrobial actions of platelet concentrates, direct interaction of the platelets with microorganisms and the participation in the antibody-dependent cell cytotocity, activation of the antioxidant responsive element, the white blood cells in direct bacterial killing, antigenspecific immune response and release of myeloperoxidases are also suggested. ${ }^{13}$

E. faecalis was chosen in this study because it is associated with most of the persistant periapical infections in clinical situations. Elimination of these infections not only depends upon the host defense but also various treatment factors. The ability of cells of E. faecalis to cause periapical disease and chronic failure may be due to their ability to invade dentinal tubules and remain viable within the tubule. ${ }^{14,15}$ Direct interaction of platelets with microorganisms and participation in antibody-dependent cell cytotoxicity and WBC's in direct bacterial killing, activation of the antioxidant responsive element, release of myeloperoxidases, and antigenspecific immune response have also been suggested. ${ }^{6,17}$ LPL is active against this microorganism even at low concentration ranges.

Candida albicans is isolated in over $80 \%$ of oral candidal lesions. In the present study, we observed that LPL was active against $C$. albicans at higher platelet concentration than those effective against the various other bacteria tested. This result is consistent with the findings of Tang et al. that the antimicrobial activity of seven antimicrobial peptides obtained from human platelets were more potent against bacteria than fungi. ${ }^{12,18}$

LPL is effective against Bacillus subtillis in a concentration similar to that of candida albicans. Its antibacterial action is due to the Truncation of CTAP -III and NAP-2 at their C- terminus generates two additional peptides, thrombocidins-1 and -2, which are bactericidal in vitro against some strains of Bacillus subtilis.

\section{CONCLUSION}

In addition to the various established regenerative properties, this study demonstrates that LPL also possesses antibacterial activity. Therefore LPL could be potentially a useful substance in fighting against post treatment infections and might represent the linking of osteoinductive and antimicrobial activity ${ }^{19}$ From this study it was concluded that the introduction of LPL in Endodontics seems to be safe and effective. This also indicates that the introduction of this platelet concentrate in endodontic practice seems to be feasible without compromising its hemostatic property. ${ }^{20}$ 


\section{REFERENCES}

1. Drago L, Bortolin M, Vassena C, Taschieri S, Del Fabbro M. Antimicrobial activity of pure platelet-rich plasma against microorganisms isolated from oral cavity. BMC Microbiol. 2013;13:47.

2. Rozalski MI, Micota B, Sadowska B, Paszkiewicz M, Wieckowska-Szakiel M, Rozalska B. Antimicrobial/antibiofilm activity of expired blood platelets and their released products. Postepy Hig Med Dosw 2013 Apr 22;67:321-5.

3. Stuart $\mathrm{CH}$, Schwartz SA, Beeson TJ, Owatz CB. Enterococcus faecalis: Its role in root canal treatment failure and current concepts in retreatment. J Endod. 2006 Feb; 32(2):93-8.

4. Farah CS, Lynch N, McCullough MJ. Oral fungal infections: An update for the general practitioner. Aust Dent J. 2010 Jun;55 Suppl 1:48-54

5. Stein T. "Bacillus subtilis antibiotics: structures, syntheses and specific functions," Molecular Microbiology 2005;56(4):845-57.

6. Walkowiak B, Kęsy A, Michalec L. Microplate reader a convenient tool in studies of blood coagulation. Thromb Res 1997;87:95-103.

7. Moojen DJ, Everts PA, Schure RM, Overdevest EP, van Zundert A, Knape JT, et al. Antimicrobial activity of platelet-leukocyte gel against staphylococcus aureus. J Orthop Res 2008;26(3):404-10.

8. Intravia J, Allen DA, Durant TJ, McCarthy MB, Russell $\mathrm{R}$, Beitzel $\mathrm{K}$ et al.In vitro evaluation of the anti-bacterial effect of two preparations of platelet rich plasma compared with cefazolin and whole blood.Muscles Ligaments Tendons J. 2014 May 8;4(1):79-84.

9. Cole AM, Ganz T, Liese AM, Burdick MD, Liu L, Strieter RM. Cutting edge: IFN-inducible ELR-CXC chemokines display defensin-like antimicrobial activity. J Immunol. 2001;167(2):623-7.

10. Tohidnezhad M, Varoga D, Podschun R, Wruck CJ, Seekamp A, Brandenburg LO, Pufe T, Lippross S. Thrombocytes are effectors of the innate immune system releasing human beta defensin-3. Injury 2011;42:682-6.

11. Schmaier AH, Smith PM, Colman RW. Platelet C1inhibitor. A secreted alpha-granule protein. J Clin Invest 1985;75(1):242-50.
12. Tang YQ, Yeaman MR, Selsted ME. Antimicrobial peptides from human platelets. Infect Immun. 2002;70:6524-33.

13. Karde PA, Sethi KS, Mahale SA, Khedkar SU, Patil AG, Joshi CP. Comparative evaluation of platelet count and antimicrobial efficacy of injectable platelet-rich fibrin with other platelet concentrates: An in vitro study.J Indian Soc Periodontol. 2017 Mar-Apr; 21(2): 97-101.

14. Sjogren U, Figdor D, Persson S, Sundqvist G. Influence of infection at the time of root filling on the outcome of endodontic treatment of teeth with apical periodontitis. Int Endod J 1997;30:297-306.

15. Haapasalo M, Udnæs T, Endal U. Persistent, recurrent, and acquired infection of the root canal system posttreatment. Endodontic Topics 2003;6:29-56.

16. Bielecki TM, Gazdzik TS, Arendt J, Szczepanski T, Krol W, Wielkoszynski T. Antibacterial effect of autologous platelet gel enriched with growth factors and other active substances: An in vitro study. J Bone Joint Surg $\mathrm{Br}$ 2007;89(3):417-20.

17. Anitua E, Andia I, Ardanza B, Nurden P, Nurden AT. Autologous platelets as a source of proteins for healing and tissue regeneration. Thromb Haemost 2004;91(1):415.

18. Kumar J, Sharma R, Sharma M, Prabhavathi V, Paul J, Chowdary CD. Presence of Candida albicans in Root Canals of Teeth with Apical Periodontitis and Evaluation of their Possible Role in Failure of Endodontic Treatment. J Int Oral Health. 2015; 7(2): 42-45.

19. Burnouf T, Chou ML, Wu YW, Su CY, Lee LW. Antimicrobial activity of platelet (PLT)- poor plasma, PLT-rich plasma, PLT gel, and solvent/detergent-treated PLT lysate biomaterials against wound bacteria. Transfusion. 2013 Jan;53(1):138-46.

20. Del Fabbro M, Ceresoli V, Lolato A, Taschieri S. Effect of platelet concentrate on quality of life after periradicular surgery: A randomized clinical study. J Endod. 2012 Jun;38(6):733-9. 
Cite this article as:

Kumar A, Suganya TL. Evaluation of Antimicrobial Efficacy of Lyophilized

Platelet Lysate against Organisms Isolated from Infected Root Canals: An in vitro Study. Int Healthcare Res J 2018;1(11):355-360.

\section{$\underline{\text { AUTHOR AFFILIATIONS }}$}

1. Post Graduate Student

2. Professor

Rajas Dental College and Hospital, Thirurajapuram, Kavalkinaru

\section{Corresponding Author:}

\section{Dr. Suganya TL}

\section{No 16}

Darshan's Home, Eden City

Tirumalnagar, Perumalpuram post,

Tirunelveli, Kanyakumari- 629001

For manuscript enquiry/author contact details, e-mail at: maunscriptenquiry.ihrj@gmail.com

\section{LEGENDS}

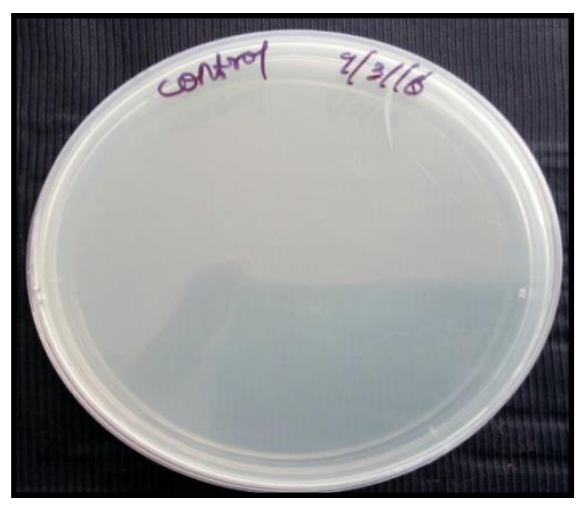

A

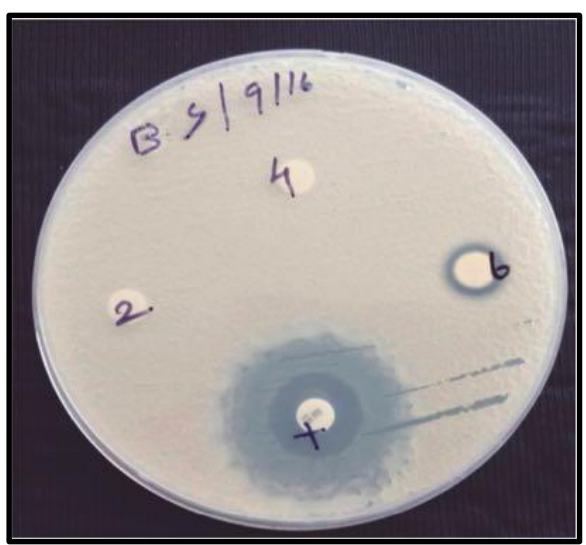

C

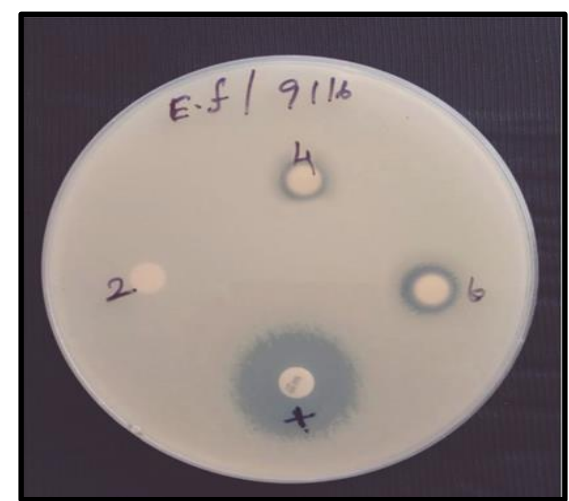

B

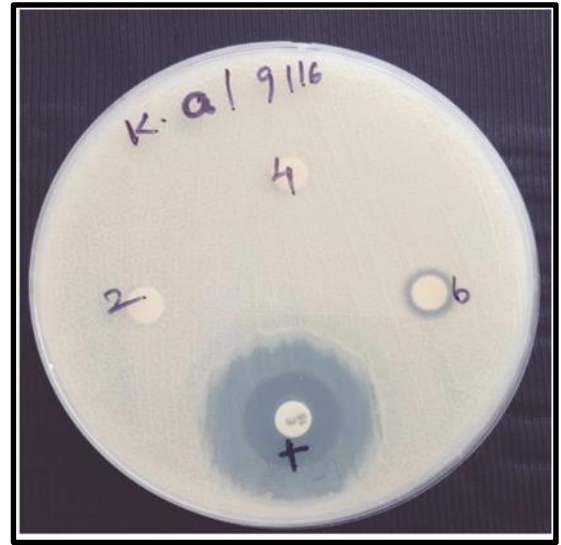

$\mathrm{D}$

Figure 1. Fig 1. Minimum inhibition Zone (MIZ) of three organisms in Luria Bertani agar:.2 - 2omg LPL; 4 - 4omg LPL; 6 - 6omg LPL :+ - Known standard antibiotic (Tetracycline, Amphotericin)

(A): Media control (B):MIZ of E faecalis, (C) MIZ of Bacillus subtilis (D) MIZ of Candida albicans 


\begin{tabular}{|c|c|c|c|c|}
\hline \multirow[t]{2}{*}{ KEY } & \multirow[t]{2}{*}{ LPL } & \multicolumn{3}{|c|}{ PATHOGENS AND ACTIVITY (ZONE OF INHIBITION } \\
\hline & & E. faecalis & C. albicans & B. subtilis \\
\hline$* /+$ & $\begin{array}{c}\text { Standard known } \\
\text { antibiotic }\end{array}$ & $25 \mathrm{~mm}$ & $22 \mathrm{~mm}$ & $18 \mathrm{~mm}$ \\
\hline 2 & $20 \mathrm{mg} / \mathrm{ml}$ of $\mathrm{LPL}$ & - & - & - \\
\hline 4 & $40 \mathrm{mg} / \mathrm{ml}$ of $\mathrm{LPL}$ & $3 \mathrm{~mm}$ & - & - \\
\hline 6 & $60 \mathrm{mg} / \mathrm{ml}$ of LPL & $8 \mathrm{~mm}$ & $6 \mathrm{~mm}$ & $2 \mathrm{~mm}$ \\
\hline
\end{tabular}

Table 1. Showing minimum inhibitory concentration of LPL for the three organisms

\begin{tabular}{|c|c|c|c|}
\hline & E.feacalis & C.albicans & B.subtilis \\
\hline Test 1 & 58 & 54 & 36 \\
\hline Test 2 & 50 & 54 & 40 \\
\hline Test 3 & 54 & 36 & 46 \\
\hline
\end{tabular}

Table 2. Minimum inhibition Zone formed by three organisms at various concentrations 